\title{
Autosomal dominant hypoparathyroidism: a proband with concurrent nephrogenic diabetes insipidus
}

\author{
A G W HUNTER*+, H HEICK $†$, W J POZNANSKI§, AND \\ P N MCLAINE $\ddagger$
}

From the Divisions of Genetics* and Biochemistry $\dagger$, and Department of Pediatrics + , Children's Hospital of Eastern Ontario; and the Department of Biochemistry, Ottawa. Civic Hospital §, and the University of Ottawa, On'tario, Canada

SUMMARY In this paper we report an extended family with well documented autosomal dominant hypoparathyroidism which was ascertained through a proband with coincident nephrogenic diabetes insipidus. Clinical findings were limited to a slight decrease in overall stature and to clinical signs of hypocalcaemia. Intelligence was normal and two patients were asymptomatic. Published reports have established that autosomal dominant, autosomal recessive, and sex linked recessive familial isolated hypoparathyroidism exist. However, in almost half the reported families an X linked dominant aetiology cannot be excluded and, at present, clinical criteria provide only minimal aid in distinguishing between the different genetic types. There remains a need for detailed documentation of further families where the pattern of inheritance is clear.

The first reported cases of familial hypoparathyroidism were three sibs with associated moniliasis described by Sutphin et al in 1943. ${ }^{1}$ Subsequent reports have established the association of hypoparathyroidism, chronic moniliasis, pernicious anaemia, Addison's disease, and probably gonadal dysgenesis as a distinct autosomal recessive condition, ${ }^{2}$ although the possibility of partial expression in heterozygotes remains. ${ }^{34}$ However, the complete clinical and genetic spectrum of isolated familial hypoparathyroidism remains to be clarified. The clinical signs range from neonatal death ${ }^{5}$ to an asymptomatic state. In some families the pattern of inheritance is clearly autosomal dominant, ${ }^{6}$ sexlinked recessive, ${ }^{5}$ or autosomal recessive. ${ }^{7-12}$ In others it cannot be deduced with certainty, which complicates the issue of clinical-genetic correlation. ${ }^{413-19}$ Finally, there were cases reported before the availability of parathormone assay where the distinction between hypoparathyroidism and pseudohypoparathyroidism is uncertain..$^{20}$ It therefore remains useful to report families with several members affected with hypoparathyroidism where the pattern of inheritance is clear.

The family described in this paper includes eight subjects with isolated hypoparathyroidism with an autosomal dominant mode of inheritance which was ascertained through a boy who also developed nephrogenic diabetes insipidus.

Received for publication 21 December 1980

\section{Case reports}

The family was of English-Canadian origin and there was no evidence of consanguinity. The proband is described in some detail because of his unusual history. The remaining family members are described briefly, together with pertinent laboratory data. The pedigree is summarised in fig 1 and the details of calcium, phosphorus, parathyroid metabolism, and the clinical course are summarised in the table and fig 2.

Parathormone was measured by the Laboratory Procedures, Esoteric Center, UpJohn Co, Kalamazoo, Michigan. The method employs guinea pig antisera raised to bovine parathormone, and patients' calcium and parathormone values are subject to discriminant analysis and compared with patients

IV

III

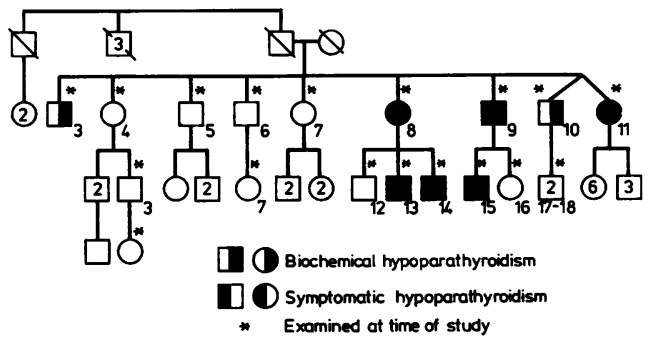

FIG.1 Family pedigree. 
TABLE Summary of calcium, phosphorus, parathormone, and clinical studies

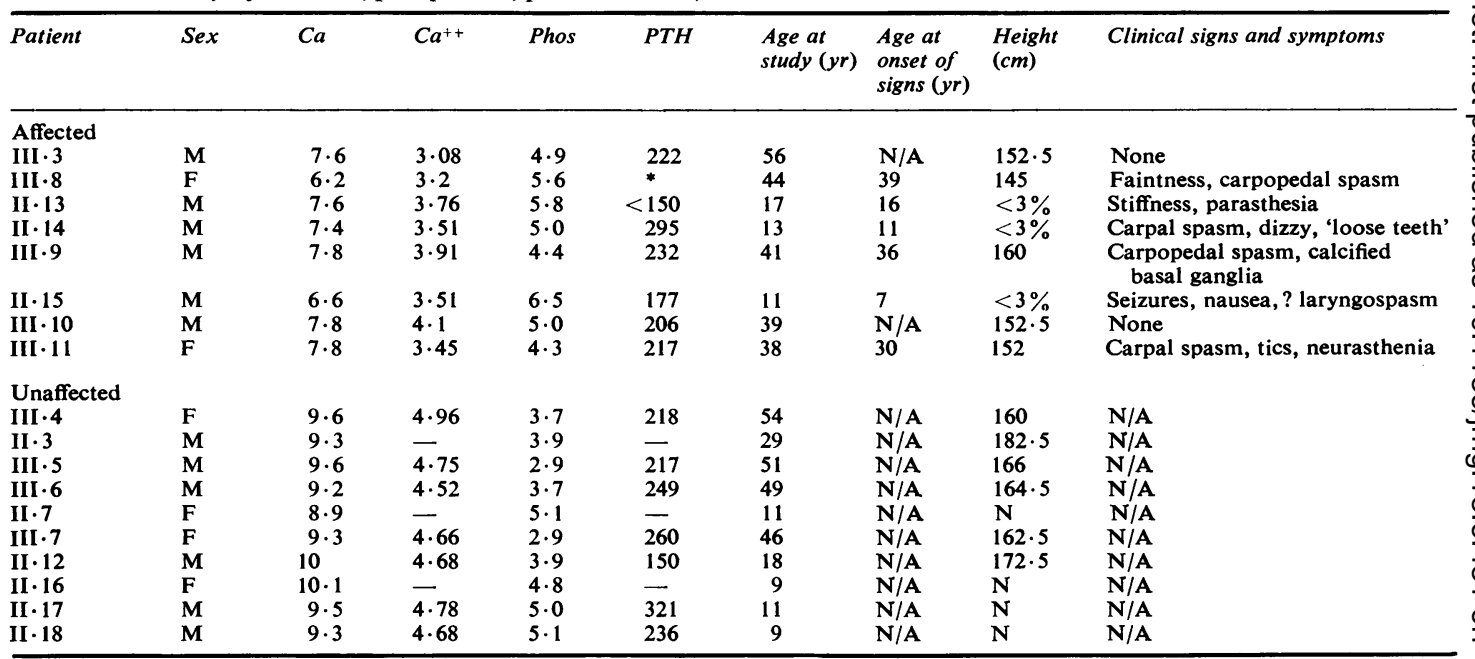

Normal ranges of biochemical studies

Calcium (Ca) 8.8-10.0 mg/dl; ionised calcium $\left(\mathrm{Ca}^{++}\right) 3.7-4.5 \mathrm{mg} / \mathrm{dl}$; phosphorus $(\mathrm{Phos})<10 \mathrm{yr}, 4.5-5.6$; $>10 \mathrm{yr} 3.6-4.6 \mathrm{mg} / \mathrm{dl}$; parathormone (PTH) see fig 2. ${ }^{*}$ Treated before PTH measured.

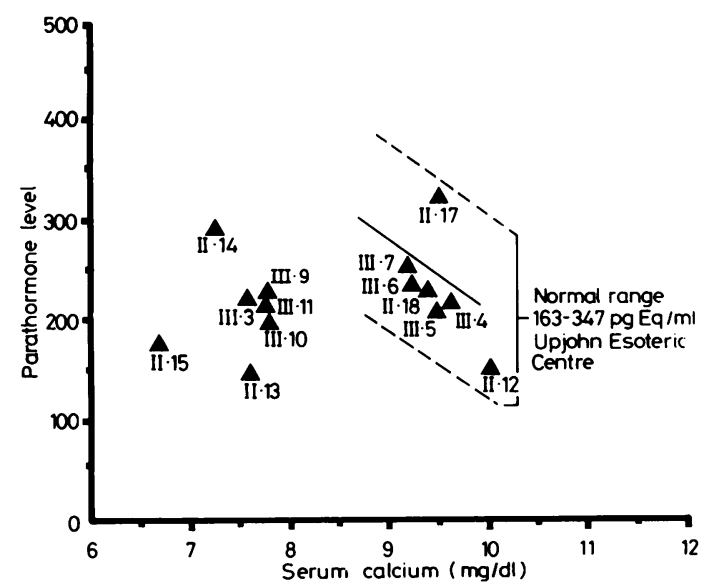

FIG 2 Summary of concurrent calcium and parathormone values in patients and normal family members. Patient numbers refer to those given in the table.

with proven parathyroid disorders. ${ }^{2122}$ Cyclic adenosine monophosphate (cyclic AMP) was measured using a kit from New England Nuclear Co, Montreal, Canada. The values were interpreted as suggested by Drezner $\mathrm{et} \mathrm{al}^{23}$ and Moses et al. ${ }^{24}$

\section{AFFECTED MEMBERS}

The proband was classified as hypoparathyroid on the basis of low serum calcium, raised phosphorus, low parathormone, and a rise in cyclic AMP in $\stackrel{\mathbb{Q}}{-}$ response to exogenous parathormone. Other family $\vec{\varphi}$ members were so classified on the basis of a para thormone level that was inappropriately low in the face of hypocalcaemia.

$I I \cdot 15$. The proband was born at term weighing $2465 \mathrm{~g}$ after a normal pregnancy and delivery. He was admitted to hospital five times during the first 3 years of life because of various acute infectious illnesses which were associated with convulsions at the ages of 2 and 3 years. Early developmental $\exists$ milestones were normal but he repeated grade 1 . In 1976 at 6 years of age he suffered a 'febrile convulsion' and was found to have positive Trousseau and Chvostek signs, possible laryngospasm, and a ç serum calcium of $6.3 \mathrm{mg} / \mathrm{dl}$ and phosphorus of $7.8 \mathrm{mg} / \mathrm{dl}$. His parathormone level was in the hypoparathyroid range (fig 2) and urinary cyclic AMP rose from a baseline value of $21 \mu \mathrm{mol} / \mathrm{g} \mathrm{Cr}$ to 300 after stimulation with exogenous parathormone. His serum calcium responded to treatment with supplemental calcium and dihydrotachysterol.

Serum and urinary calcium was monitored weekly, $N$ then bi-weekly and, after 3 months, on a monthly basis. At no time was there evidence of hyper- $N$ calcaemia or hypercalcuria. Seven months after $\mathbb{E}^{-}$ diagnosis he reported one episode of nocturia and $\sigma$ one month later presented with marked polyuria and polydypsia. His weight and height were less than the 3rd centile and his head circumference was $\stackrel{\mathcal{O}}{+}$ normal. A water deprivation test showed a maximum 0 urine specific gravity of 1.010 and osmolality of 
$440 \mathrm{mosmol} / \mathrm{kg}$ while the serum osmolality was 305 mosmol/kg. A pitressin stimulation test gave no measurable increase in urinary cyclic AMP and a diagnosis of nephrogenic diabetes insipidus was made.

A water deprivation test was performed on the mother. Her maximum urine osmolality was 810 mosmol/kg after a 14-hour fast (serum osmolality $313 \mathrm{mosmol} / \mathrm{kg}$ ) with no further increase up to 16 hours and no significant response to exogenous pitressin. There was no family history of diabetes insipidus in the mother's father or four brothers.

The patient has continued to grow at less than the 3rd centile but his overall development and school progress have been adequate. His bone age at 8.5 years was comparable to a 5-year-old and there has been no evidence of cutaneous moniliasis or associated endocrinopathy.

Relevant normal or negative studies included: blood urea nitrogen, serum creatinine, magnesium, copper, triglycerides, and cholesterol; growth hormone assay, thyroid releasing hormone studies, thyroid stimulating hormone, $\mathrm{T} 3$ resin uptake, $\mathrm{T} 4$ thyroid antibodies, am and pm cortisol, immunoglobulins, blastogenic transformation, total $\mathrm{B}$ and $\mathrm{T}$ cells, delayed skin response; Schilling test, stool fat balance, an electroencephalogram, and radiographs of the skull and hands.

$I I I \cdot 9$. At the time of the study the father was $160 \mathrm{~cm}$ tall and had a 2-year history of carpopedal spasm. He was gainfully employed until the age of 38 when he suffered a heart attack. Laboratory studies were consistent with hypoparathyroidism (table, fig 2). A skull radiograph showed calcification of the basal ganglia.

$I I I \cdot 3$. This uncle of the proband was $152.5 \mathrm{~cm}$ tall, gainfully employed, and had no signs or symptoms of hypoparathyroidism at the time of the study, despite significant hypocalcaemia (table, fig 2).

III. 8 . This aunt of the proband was $145 \mathrm{~cm}$ tall at the age of 40 years when she presented with a one-year history of weakness and carpopedal spasm. Her initial calcium was $6.2 \mathrm{mg} / \mathrm{dl}$ and she responded to calcium and vitamin $D$ supplementation. She had a longstanding history of difficulty in retaining dental fillings for more than a year. She has suffered at least two episodes of hypercalcaemia $(14.3 \mathrm{mg} / \mathrm{dl})$ because of excess vitamin $D$ intake, which were accompanied by an acute rise in blood urea nitrogen $(29 \mathrm{mg} / \mathrm{dl})$ and creatinine $(2.5 \mathrm{mg} / \mathrm{dl})$. At the time of the study she was normocalcaemic and had a blood urea nitrogen of $22 \mathrm{mg} / \mathrm{dl}$. After 16 hours of water deprivation her urine osmolality was $347 \mathrm{mosmol} / \mathrm{kg}$ with a serum osmolality of $299 \mathrm{mosmol} / \mathrm{kg}$. She complained of polyuria and polydypsia. Parathyroid stimulation resulted in an increased urinary phosphate excretion, increased tubular reabsorbtion of phosphate, and a rise in cyclic AMP.

Relevant normal or negative studies included: serum magnesium, albumin, and uric acid; T3 resin uptake, T4, thyroid antibodies, cortisol, prolactin; stool fat balance and duodenal biopsy with assay of lactase, invertase, and maltase; stool and urine calcium and skeletal survey except for an osteochondroma of the right clavicle.

All of her sons (II·12, II $13, \mathrm{II} \cdot 14)$ had a Meckel diverticulum.

$I I \cdot 13$. This son of III $\cdot 8$ was evaluated at the age of 9 years because his height and weight were below the 3rd centile. He complained of abdominal pain and reflexes were noted to be brisk, but serum calcium was not measured. His school performance was adequate and medical history unremarkable until the age of 16 years when he presented with a 3-month history of stiffness and parasthesiae. He was $140 \mathrm{~cm}$ tall ( $<3$ rd centile) and no other physical abnormalities were noted. His serum calcium was $7 \cdot 4$ $\mathrm{mg} / \mathrm{dl}$ and phosphorus $7.7 \mathrm{mg} / \mathrm{dl}$, and a parathyroid stimulation test showed a rise of urinary cyclic AMP from 1.2 to $157 \mu \mathrm{mol} / \mathrm{g} \mathrm{Cr}$ after one hour. $\mathrm{He}$ responded well to calcium and vitamin $\mathrm{D}$ supplementation. Additional negative and normal findings included: blood urea nitrogen, serum creatinine, creatinine clearance, uric acid, total protein and albumin, sweat chloride, radiographs for bone age and of the upper gastrointestinal tract, and growth homone stimulation.

$I I \cdot 14$. The youngest son of III 8 was 11 years old and asymptomatic at the time of diagnosis (table, fig 2). School progress had been normal. One year later he presented in carpopedal spasm and also complained of dizziness, headaches, and loose teeth. He was $136.5 \mathrm{~cm}$ tall $(<3 \mathrm{rd}$ centile). A history of failure to take medications was obtained. Normal studies included serum magnesium, blood urea nitrogen, creatinine clearance, and a radiographic skeletal survey.

$I I I \cdot 10$. This uncle of the proband was 30 years old, $152.5 \mathrm{~cm}$ tall, gainfully employed, and asymptomatic at the time of the study when he showed biochemical evidence of hypoparathyroidism (table, fig 2).

III 11 . This aunt of the proband presented at 38 years of age with a 7- to 8-year history of carpopedal spasm and spontaneous twitching. She was $152 \mathrm{~cm}$ tall and had no other significant medical complaints. Her laboratory findings were compatible with hypoparathyroidism (table, fig 2). Additional normal laboratory studies included T3 resin uptake, T4, serum cortisol, negative thyroid globulin and microsomal antibodies, and a skull radiograph.

Her children were not available for study, but at least one was reported to be symptomatic. 
UNAFFECTED MEMBERS

The biochemical findings and heights of additional family members who were studied and found to be normal are summarised in the table and fig 2.

\section{Discussion}

The biochemical studies in our patients have clearly established the diagnosis of hypoparathyroidism. Pseudohypoparathyroidism is ruled out by the increased urinary cyclic AMP response to exogenous parathormone administration in the three patients tested. Several of the patients had studies to exclude malabsorption, renal disease, and hypomagnesaemia. There was no evidence of monilial infection or an associated endocrinopathy.

In our family there were three proven and one probable examples of vertical transmission, one instance of male-to-male transmission, and one example of an affected male failing to transmit the condition to his daughter. Autosomal dominant inheritance seems established. The family reported by Barr $e t a l^{6}$ contains the only previous report of male-to-male transmission of documented hypoparathyroidism. The two affected children were of normal height but retarded; the father was of normal intelligence and it is possible that the retardation was unrelated to the hypoparathyroidism. Nichols et al $^{\mathbf{2 0}}$ reported a large family with autosomal dominant inheritance (failed male-to-female transmission) but the differentiation between hypoparathyroidism and pseudohypoparathyroidism was uncertain. A number of additional families have been reported with vertical transmission of hypoparathyroidism, ${ }^{613-19}$ but in each the affected parent has been female. This remarkable female preponderance could reflect a sex linked dominant mode of inheritance. In general, the mothers are less severely affected than their children, but this is probably simply an ascertainment bias as there is no tendency for males to be more severely affected than their female sibs. It does not appear possible to subdivide these families on clinical grounds as the intrafamilial variation in clinical signs is as great as that seen between families. Another possible explanation for this excess of females among affected parents may be that signs and symptoms appear earlier and are more significant in females than in males, as in our family (table).

Sex linked recessive inheritance is apparent in the family reported by Peden ${ }^{5}$ and, at least in the original family, it was characterised by severe neonatal seizures and many cases of neonatal death. The author pointed to an excess of males with idiopathic neonatal hypoparathyroidism.

Autosomal recessive inheritance appears likely in the remaining familial cases, ${ }^{7-12}$ although the investigation of the families is not always complete.
Symptoms in our family were limited to manifestations of hypocalcaemia, such as carpopedal spasm, $\stackrel{\mathbb{\Phi}}{+}$ twitching, or parasthesia One affected woman $\Rightarrow$ (III.8) and her son complained of difficulty in $\stackrel{?}{?}$ retaining dental fillings and III.9 had evidence of $\mathrm{C}$ basal ganglia calcification. All affected members $\frac{\bar{\sigma}}{\bar{R}}$ were of normal intelligence and there was no $\frac{\bar{s}}{\vec{D}}$ evidence of skeletal dysplasia or cataract.

There is some evidence that the hypoparathyroidism may have resulted in a decrease in overall ${ }^{\infty}$ height: Il $13, \mathrm{II} \cdot 14$, and the proband were all below. the 3rd centile, whereas their sibs were of normal $\vec{\omega}$ height. The affected adult males averaged $152.8 \mathrm{~cm} \stackrel{\text { S }}{ }$ and females $147.5 \mathrm{~cm}$, compared to their sibs who averaged $165 \mathrm{~cm}$ and $156.5 \mathrm{~cm}$, respectively. The. earlier onset of symptoms in generation II compared $\vec{\infty}$ to generation III is likely to be a reflection of ascertainment bias. So far it does not appear possiblew to use clinical presentation to distinguish clearly the possible different genetic types of hypopara-? thyroidism. On average, the age of onset is older in $\vec{\square}$ the autosomal than in the sex linked recessive varietyd and both appear earlier than in the proven autosomale dominant families, but numbers remain small and $\frac{\vec{b}}{6}$ overlap so large as to make this unhelpful as $\mathrm{a}^{\mathbb{D}}$ differential criteria. Nor are the presence or absence $\overrightarrow{0}$ of calcification of the basal ganglia or cataragts helpful. Three of the autosomal recessive families had enamel hypoplasia and two had hypomagnesaen These signs may prove to be of differential signifi-s cance. The cases reported by Goldman et al ${ }^{4}$ could be sex linked recessive but are more likely to be autosomal recessive if these clinical signs are valid? However, to add to the confusion there were distan $\overrightarrow{\vec{b}}$ relatives in this family who suffered from Addison's disease but had normal parathyroid function.

The proband in this family had nephrogenic. diabetes insipidus. This cannot be accounted for or the basis of hypercalcaemia as a result of treatmento There was only one brief episode of hypercalcaemia which occurred after the onset of the diabetes. insipidus. Although haematuria ${ }^{19}$ and nephrosis ${ }^{20}$ have been reported in patients with familial hypo $₹$ parathyroidism, the association with diabetes insipidus seen in our patient does not appear to haves been previously reported. The poor maternal urinari. concentrating ability suggests that hypoparathyf roidism was a chance association with $X$ linked nephrogenic diabetes insipidus, although there is nळ support for this from the family history. Hyperes calcuria as a complication of therapy may cause diabetes insipidus. This appears to have occurred io the case of III $\cdot 8$, but the proband, as discussed above was closely monitored and had no significant hypercalcaemia.

The onset of renal impairment in III. 8 emphasise 
the need for very close monitoring of patients whose hypocalcaemia is being treated. This is especially true with the use of potent vitamin D preparations and at times when dosages are changed. Such renal complications may be life threatening and one can question the need to treat patients who are minimally or not at all symptomatic from their hypocalcaemia.

We would like to thank the members of the $\mathrm{L}$ family who co-operated in this study and also Dr Anna Sharpe who referred the proband to us. We are also grateful to Ms B Greenberg for typing the manuscript.

\section{References}

1 Sutphin A, Albright F, McCune DJ. Five cases (three in siblings) of idiopathic hypoparathyroidism associated with moniliasis. J Clin Endocrinol 1943;3:625-34.

2 Nusynowitz MI, Frame B, Kolb FO. The spectrum of hypoparathyroid states: a classification based on physiological principles. Medicine 1976;55:105-19.

3 Chaptal J, Jean R, Bonnet R, Guillaumot R, Morel G. Hypoparathyrodie familial. Etudes clinique, biologique et thérapeutique. Arch Fr Pediatr 1960;17:866-78.

* Goldman R, Reynolds JL, Cummings HR, Bassett SH. Familial hypoparathyroidism. JAMA 1952;150:1104-6.

5 Peden VH. True idiopathic hypoparathyroidism as a sex-linked recessive trait. Am $J$ Hum Genet 1960;12: 323-37.

6 Barr DG, Prader A, Esper U, Rampini S, Marrian VJ, Forfar JO. Chronic hypoparathyroidism in two generations. Helv Paediatr Acta 1971;26:507-21.

7 Bronsky D, Kiamko RT, Waldstein SS. Familial idiopathic hypoparathyroidism. J Clin Endocrinol Metab $1968 ; 28: 61-5$.

${ }^{8}$ Forbes GB. Clinical features of idiopathic hypoparathyroidism in children. Ann NY Acad Sci 1956;64:432-55.

9 Hansted C, Brandt S. Electroencephalographic changes with hypocalcemia due to hypoparathyroidism. Electroencephalogr Clin Neurophysiol 1952;5:101-4.

10 Niklasson E. Familial early hypoparathyroidism associated with hypomagnesaemia. Acta Paediatr Scand 1970;59:715-9.

11 Richter PL, Chutorian AM. Familial hypoparathyroidism.
Case reports and a review of the literature. Neurology $1968 ; 18: 75-80$.

12 Taybi H, Keele D. Hypoparathyroidism: a review of the literature and report of two sisters, one with steatorrhea and intestinal pseudo-obstruction. $A m \mathrm{~J}$ Roentgenol $1962 ; 88: 432-42$.

13 Barwich D. Familiar vorkommender hypoparathyroidismus. Med Klin 1974;69:2029-32.

14 Benson PF, Parsons V. Hereditary hypoparathyroidism presenting with oedema in the neonatal period. $Q J \mathrm{Med}$ $1964 ; 33: 197-208$.

15 Buist N, Cox K. Dominantly inherited parathormone sensitive hypoparathyroidism. Am J Hum Genet 1974;26: $18 \mathrm{~A}$.

16 Gerlóczy F, Moinár M, Bizsik G, Nádor V. Szathmáry S, Zur frage der familiarstat des hypoparathyroeidismus. Acta Paediatr Acad Sci Hung 1966;8:83-111.

17 Gorodischer R, Aceto T Jr, Terplan K. Congenital familial hypoparathyroidism. Management of an infant, genetics, pathogenesis of hypoparathyroidism, and fetal undermineralization. Am J Dis Child 1970;119:74-8.

18 Kruse K, Offermann G. Zur klinik und behandlung des familiaren idiopathischen hypoparathyreoidismus. Monatsschr Kinderheilkd 1977;125:489-90.

19 Lelong M, Canlorbe P, Vinh LT, et al. Hypoparathyrodie familiale. Ann Pediatr 1962;38:222-32.

20 Nichols FL, Holdsworth DE, Reinfrank RF. Familial hypocalcemia, latent tetancy and calcification of the basal ganglia. Am J Med 1961;30:518-28.

21 Blair AJ, Hawker CD, Uttinger RD. Ectopic hyperparathyroidism in a patient with metabolic hypernephroma. Metabolism $1973 ; 22: 147-54$.

22 Hawker CD. Parathyroid hormone: radioimmuno-assay and clinical interpretation. Ann Clin Lab Sci 1975;5: 383-98.

23 Drezner MK, Neelon FA, Curtis HB, Lebovitz HE. Renal cyclic adenosine monophosphate, an accurate index of parathyroid function. Metabolism 1976;25:1103-12.

24 Moses AM, Breslan N, Coulson R. Renal responses to PTH in patients with hormone-resistant (pseudo) hypoparathyroidism. Am J Med 1976;61:184-9.

25 Barakat AY, D'Albora JB, Martin MM, Jose PA. Familial nephrosis, nerve deafness, and hypoparathyroidism. J Pediatr 1977:91:61-4.

Requests for reprints to Dr A G W Hunter, Division of Genetics, Children's Hospital of Eastern Ontario, 401 Smyth Road, Ottawa, Ontario, Canada KIH 8L1. 